\title{
Technology in emergency and disaster medicine. Telemedicine. Virtual reality. The role of simulation in the improvement of human factors associated to the risk of medical errors
}

\author{
Tehnologia în medicina de urgenţă şi catastrofă. Telemedicina. \\ Realitatea virtuală. Rolul simulării în ameliorarea factorilor umani asociaţi riscului de \\ producere a erorilor medicale
}

\author{
Cristian Boeriu', Raed Arafat ${ }^{2}$, Sorana Truța', Emilia Turucz ${ }^{1}$ \\ ${ }^{1}$ Universitatea de Medicină, Farmacie, Ştiinţe şi Tehnologie „George Emil Palade“, Tg. Mureş, România \\ ${ }^{2}$ Departamentul pentru Situaţii de Urgenţă, Ministerul Afacerilor Interne, România
}

\begin{abstract}
Both emergency medicine and disaster medicine have long been connected by technology. To take advantage of the benefits, technology should be considered as part of an integrated team to deliver clinical care to patients. Moreover, technology enabled learning systems, such as virtual reality, simulations or educational games, are commonly used not only as medical training tools but also to improve the human factors associated to the risk of medical errors. Disaster management makes use of multiple technologies to provide services in the disaster zones. The idea of using telemedicine in emergency and disaster situations has been around for more than four decades. Virtual reality represents an efficient alternative technique for training programs in disaster management for every learning stages. Simulation-based Crew Resource Management (CRM) training was found to be effective in the improvement of the non-technical skills and clinical performance of the interprofessional emergency teams.
\end{abstract}

Keywords: technology, telemedicine, simulation, virtual reality, crew resource management

REZUMAT
Medicina de urgenţă şi medicina de dezastre sunt de mai mult timp conectate prin tehnologie. Pentru a bene-
ficia de avantajele oferite de tehnologie, aceasta trebuie considerată ca parte integrantă a echipelor care
asigură asistenţa medicală. Mai mult decât atât, sistemele educaţionale bazate pe tehnologie, cum ar fi reali-
tatea virtuală, simularea, jocurile pe computer, nu sunt utilizate doar ca instrumente de învăţare a unor tehnici
medicale, ci şi pentru ameliorarea factorilor umani asociaţi riscului de producere a erorilor medicale. Manage-
mentul dezastrelor foloseşte tehnologii multiple pentru a asigura serviciile necesare în zonele calamitate.
Ideea de a utiliza telemedicina în gestionarea situaţiilor de urgenţă şi dezastre a apărut în urmă cu mai bine
de 40 de ani. Realitatea virtuală reprezintă o alternativă de instruire eficientă în medicina de urgenţă şi dez-
astre, la toate nivelurile de învăţare. Instruirea Crew Resource Management (CRM) bazată pe simulare s-a
dovedit a fi utilă pentru îmbunătăţirea abilităţilor nontehnice şi a performanţelor clinice a echipelor medicale
de urgenţă.

Cuvinte cheie: tehnologie, telemedicină, simulare, realitate virtuală, crew resource management

\section{INTRODUCERE}

Tehnologia informaţiei în domeniul medical asigură managementul computerizat şi schimbul securizat de date medicale între structurile sanita- re, pacienţi şi alte entităţi, cum sunt companiile de asigurări sau agenţiile guvernamentale.

Utilizarea tehnologiei informaţiei creşte calitatea, siguranţa şi eficienţa serviciilor de sănătate prin îmbunătăţirea accesului la aceste servicii, 
reducerea costurilor, prevenirea erorilor medicale şi eficientizarea segmentului administrativ prin reducerea utilizării documentaţiei în format scris și/ sau tipărit.

În plus faţă de beneficiile descrise mai sus, tehnologia informaţiei în medicină îmbunătăţeşte nivelul de asistenţă medicală acordată pacienţilor prin asigurarea interoperabilităţii sistemelor informatice disponibile în unităţi sanitare aflate chiar în ţări diferite.

\section{TELEMEDICINA}

Telemedicina reprezintă un exemplu concret de implicare a tehnologiei în schimbul de informaţii medicale între diferite locaţii, utilizând sistemele informatice şi de telecomunicaţii. Aceasta contribuie la îmbunătăţirea asistenţei medicale pentru persoanele aflate la distanţă de unităţile sanitare şi nu au acces facil la servicii medicale.

Implementarea sistemului de telemedicină în România a început printr-un proiect pilot iniţiat la Târgu Mureş în anul 2003. Proiectul a constat în dotarea echipajelor paramedicale de prim ajutor calificat SMURD cu un sistem de transmisie în timp real a datelor medicale din prespital la Unitatea de Primire Urgenţe (UPU) din structura Spitalului Clinic Judeţean de Urgenţă Târgu Mureş. La acest nivel, datele transmise (puls, tensiune arterială, frecvenţă respiratorie, pulsoximetrie, monitorizare cardiacă, ECG pe 12 canale) erau analizate în timp real de unul dintre medicii de urgenţă din UPU, care decidea apoi tratamentul care trebuia aplicat pacientului şi spitalul la care urma să fie transportat.

După patru ani de evaluare, timp în care sistemul şi-a demonstrat eficienţa, la nivelul Ministerului Sănătăţii a fost luată decizia de a dota toate ambulanţele de tip B (deservite de paramedici pompieri şi asistenţi medicali din cadrul Serviciilor Județene de Ambulanţă) cu echipamente de transmisie date, conectate la centre regionalizate de recepţie integrate cu Unităţile de Primiri Urgenţe sau cu Sistemul Naţional Unic pentru Apeluri de Urgenţă 112.

Sistemul de telemedicină prespitalicească a fost întregit în anul 2009 cu unul care interconecta, în faza iniţială, structurile de primire a urgenţelor din 41 de spitale din Regiunea Centru a României, fiind extins ulterior la peste 100 de spitale situate în alte două regiuni. Scopul acestui sistem este acela de a veni în sprijinul medicilor fără specialitate de medicină de urgenţă care deservesc structurile de primire a urgenţelor din spitalele mici. Tehnologia utilizată permite interacţiunea audio şi video, în timp real, între medicul curant din teritoriu şi medicii specialişti din centrul de recepţie aflat într-un spital universitar, facilitându-se astfel luarea celor mai bune decizii în ceea ce priveşte tratamentul de urgenţă al pacienţilor şi eventualul lor transfer întrun centru medical avansat.

Sistemul de telemedicină din România este în continuă dezvoltare, urmând să fie extins la nivel naţional.

În cazul producerii unui dezastru, telemedicina oferă medicilor aflaţi în diferite colţuri ale lumii posibilitatea de a oferi servicii medicale la distanţă victimelor aflate în zona calamitată. Acest lucru a fost făcut posibil prin crearea sistemului multinaţional de telemedicină, care angrenează, într-o structură unitară, servicii de telemedicină care utilizează tehnologii diferite, prin asigurarea interoperabilităţii între acestea.

Serviciile de telemedicină pot fi împărţite în două categorii: servicii audio/video şi servicii de schimb de informaţii medicale. Serviciile audio/ video asigură transmiterea informaţiilor prin linii telefonice sau prin conexiuni video cu capabilităţi audio, iar cele de schimb de informaţii medicale asigură transmisia de date medicale propriu-zise, cum ar fi semnele vitale.

La toate acestea se adaugă posibilitatea de achiziţie, stocare şi transmitere a informaţiilor medicale (date, imagini, sunete, video) către o altă locaţie la nivelul căreia se află personalul medical calificat care va asigura evaluarea clinică. În cazul unui dezastru, transmisia datelor se face printr-o conexiune robustă prin satelit [1].

\section{REALITATEA VIRTUALĂ}

Intervenţiile în cazul dezastrelor se desfăşoară într-un mediu necunoscut, atât din punctul de vedere al terenului de lucru afectat de un eveniment neobişnuit, cât şi din perspectiva personalului de intervenţie, acesta provenind de multe ori din instituţii diferite şi cu nivel de instruire necunoscută.

Pregătirea în managementul dezastrelor trebuie să cuprindă obligatoriu, pe lângă întocmirea competenţelor practice specifice individuale, şi dezvoltarea abilităţilor nontehnice de comunicare, organizare şi coordonare la orice nivel.

Un aspect important al formelor de pregătire în acest domeniu este menţinerea competenţelor pe termen lung. Expunerea personalului de intervenţie la astfel de evenimente nu se întâmplă de rutină, şansele de acumulare a experienţelor fiind, din acest motiv, reduse. Pregătirea pentru dezastre tre- 
buie să cuprindă un plan de reîmprospătare a informaţiilor şi a abilităţilor practice. O modalitate dovedită deja pentru a menţine competenţele în acest domeniu este participarea la exerciţiile de teren în mod regulat.

$\mathrm{Au}$ fost create scale de evaluare globală ca indicatori potenţiali ai competenţei de pregătire generală în cadrul educaţional, utilizând simulări de fidelitate crescută. Astfel de instrumente, cu utilizarea unor sisteme de scoruri adecvat definite, ar trebui să ajute la evaluarea competenţelor în răspunsul de bază la dezastre, în combinaţie cu exerciţii de dezastru cu multiple manechine complet imersive [2].

Realitatea virtuală reprezintă o alternativă promiţătoare pentru programele de formare în managementul dezastrelor, aplicabilă în toate etapele de instruire, începând de la cursuri teoretice sau ateliere practice specifice şi până la dezvoltarea exerciţiilor complexe, multidisciplinare, cu integrarea întregului sistem de comandă şi control.

Termenul de realitate virtuală este adesea folosit ca un mijloc de mediu virtual complet imersiv. De fapt, realitatea virtuală este un concept care se realizeaza prin intermediul unui simulator.

Simulatoarele sunt definite ca un ansamblu de software, hardware, aparate şi dispozitive prin care se poate reproduce o situaţie sau un sistem tehnic în mediul virtual într-un mod interactiv, permiţând dezvoltarea scenariilor pe toate tipurile de dezastre, inclusiv a unor situaţii excepţionale, foarte greu sau imposibil de realizat altfel în cadrul exerciţiilor reale de teren. Scenariile create pot fi reutilizate parţial sau integral de câte ori este nevoie şi se pot adapta uşor pentru diferite grupe de audienţă sau obiective noi de instruire.

Realitatea virtuală este utilizată pentru instruire încă din anii 1960, experimentată iniţial pentru antrenarea piloţilor şi a militarilor, tehnica s-a dezvoltat rapid şi, pe lângă latura de divertisment, este tot mai frecvent utilizată în programele educaţionale în diverse specialităţi [3].

Realitatea virtuală este un mediu interactiv, tridimensional, generat de un computer, care permite individului explorarea ambientului prin simţuri vizuale şi auditive, respectiv manipularea unor obiecte sau realizarea unor acţiuni predeterminate. Persoana sau grupul ,scufundat“ în acest mediu virtual pot experimenta orice situaţie periculoasă, costisitoare sau nepractic de realizat în lumea reală.

Tehnologia realităţii virtuale s-a dezvoltat exploziv în ultimii ani. Prin adăugarea dispozitivelor de sincronizare a simţurilor, gradul de imersie în mediul virtual al individului se poate creşte semni- ficativ. Ţinta este aceea de a realiza o combinaţie perfectă de hardware, software şi de sincronizare senzorială pentru a asigura un simţ al prezenţei, adică participanţii să simtă că fac parte din acel mediu virtual.

Capacitatea de a crea personaje (de exemplu, avatare ca pacienţi sau personal de răspuns la urgenţă) şi de a adapta mediul scenariilor la caracteristicile geografice, meteorologice şi comportamentale ale unei situaţii date face ca un soft de realitate virtuală să fie utilizabil şi pentru dezvoltarea scenariilor şi derularea exerciţiilor de simulare în cadrul formării pentru răspuns la dezastre.

În cadrul exerciţiilor de simulare pentru managementul dezastrelor, importanţa terenului virtual de antrenament constă în potenţialul de a reproduce cât mai realist stresul psihic creat de impactul vizual al situaţiei. Totuşi, utilizarea unui mediu virtual mai puţin complex, prin ignorarea detaliilor neimportante, poate asigura un nivel suficient de angajament psihologic în rândul participanţilor [4]. Mediul virtual doar prin interfaţa ecranului a fost folosit în mai multe studii pentru antrenarea personalului medical în efectuarea triajului medical în situaţii de dezastre, iar eficacitatea şi nivelul de implicare a participanţilor sunt comparabile cu exerciţiile de teren, în favoarea costurilor reduse [5-7].

Realitatea virtuală poate oferi o învăţare bazată pe experienţă, care le permite participanţilor să observe consecinţele acţiunilor lor [8]. În mediul virtual, cursanţii se deplasează în mod autonom şi se angajează în activităţi autodirijate în contextul lor de învăţare sau experimentează consecinţele acţiunilor lor, învăţând prin aceste procese [9]. Prin urmare, acest lucru poate duce la o mai mare eficacitate a formării [10].

Simulările şi atelierele practice în mediul virtual asigură un mod de instruire sigură, eficientă şi, nu în ultimul rând, cost-eficientă pentru formarea profesională a personalului de intervenţie pentru situaţii de urgenţă. Este o metodă frecvent utilizată atât pentru antrenarea, cât şi pentru evaluarea individuală periodică a competenţelor specifice din acest domeniu profesional. Mai mult, prezintă un potenţial de explorat pentru dezvoltarea exerciţiilor complexe multidisciplinare de dezastre asemănătoare exerciţiilor de teren.

Un potenţial de explorat este utilizarea realităţii virtuale în contextul exerciţiilor complexe, multidisciplinare şi multinivel. De exemplu, poate fi utilă în dezvoltarea unor exerciţii de simulare complexe, efectuate simultan în mai multe locaţii, provocate de un eveniment de amploare şi unificat 
de răspunsul integrat la dezastre, care implică mai multe organizaţii şi care răspund în mai multe jurisdicţii.

Apariţia abordărilor bazate pe tehnologie pentru formarea în caz de răspuns la dezastre, prin intermediul realităţii virtuale, pare a fi promiţătoare în capacitatea sa de a reduce lacunele metodelor de formare utilizate în mod obişnuit.

\section{ROLUL SIMULĂRII ÎN AMELIORAREA FACTORILOR UMANI ASOCIATI RISCULUI DE PRODUCERE A ERORILOR MEDICALE}

În ciuda evoluţiei medicinei moderne, în special în ceea ce priveşte diagnosticul şi tratamentul diferitelor boli, numărul pacienţilor afectaţi de erori medicale este nepermis de mare. De fapt, erorile medicale sunt pe locul 8 drept cauză de deces în SUA, iar datele din alte ţări sunt similare [11]. Numărul real al pacienţilor expuşi unor erori medicale este mult mai mare, dar unii sunt mai norocoşi şi nu sunt afectaţi în mod evident de acestea [12]. Ca urmare, siguranţa pacienţilor este departe de a fi perfectă, iar ameliorarea acesteia şi dezvoltarea unei culturi a siguranţei pacientului ar trebui să reprezinte un domeniu de mare interes.

La sfârşitul anilor ,70, industria aviatică a subliniat importanţa factorilor umani, $75 \%$ dintre accidentele sau incidentele aviatice fiind atribuite erorilor umane [13]. Acest rezultat a determinat Administraţia Naţională Aeronautică şi Spaţială (NASA) să identifice aspectele erorilor umane implicate în producerea accidentelor aviatice [14]. În acest sens, s-au făcut experimente, au fost consultaţi piloţi experimentaţi şi au fost analizate din nou rapoartele accidentelor, cu scopul identificării abilităţilor/aptitudinilor care fie au contribuit la accidente, fie au fost eficiente în prevenirea lor [15].

Rezultatele acestor investigaţii au condus la crearea şi implementarea unui instrument focusat pe pregătirea în factori umani, sub forma trainingului de tip CRM (Crew Resource Management). CRM este acum un program de pregătire interprofesională obligatoriu în aviaţie, care utilizează simulatoare de înaltă fidelitate pentru a dezvolta abilităţile nontehnice ale echipele de zbor (comunicare, verificare încrucişată, monitorizare încrucişată, leadership, utilizarea resurselor şi atenţie situaţională). CRM este considerat responsabil pentru reducerea numărului catastrofelor aviatice din ultimele patru decenii $[16,17]$.

În mod similar, aproximativ $70 \%$ dintre erorile medicale sunt atribuite factorilor umani [18] (leadership ineficient, comunicare nestandardizată în echipă, lipsa atenţiei situaţionale şi a imaginii de ansamblu, folosirea neadecvată a resurselor, triajul necorespunzător, prioritizare neadecvată) $[17,19$, 20] şi nu unor greşeli tehnice [21], astfel încât ar fi logic ca pregătirea profesioniştilor în medicină să includă, pe lângă aspectele pur medicale, şi trainingul focalizat pe factorii umani şi evitarea erorilor datorate acestora.

În acest sens, s-au făcut progrese prin adoptarea şi adaptarea cursurilor de tip CRM în sfera medicală, în particular în specialităţi implicate în managementul situaţiilor critice, cu risc crescut de apariţie a erorilor: anestezia, terapia intensivă, chirurgia şi, nu în ultimul rând, medicina de urgenţă.

Obiectivul primar al CRM este îmbunătăţirea dinamicii echipei, identificarea şi schimbarea modelelor mentale care creează bariere în adoptarea: comunicării eficiente, gestionării eficiente a sarcinilor, comportamentului adecvat unui lider şi îmbunătăţirii atenţiei situaţionale [22], prin dezvoltarea sau ameliorarea abilităţilor nontehnice care sunt invers proporţionale cu şansa de apariţie a erorilor şi efectelor adverse [15]. Aceste abilităţile nontehnice pot fi definite ca ,abilităţi personale, cognitive şi sociale care completează abilităţile tehnice şi contribuie la performanţă şi siguranţă în executarea sarcinilor" [23].

În acest scop, au fost utilizate iniţial sesiunile didactice clasice, bazate pe prezentări orale sau discuţii în grupuri mici, asistate, eventual, de înregistrări video pentru iniţierea discuţiilor [24]. Deşi principiile CRM pot fi predate de către un instructor cu abilităţi bune de prezentator, aplicarea practică a cunoştinţelor este imposibilă într-un astfel de training. Pentru a acoperi acest element lipsă, au fost introduse simulările.

Eficienţa trainingului CRM bazat pe simulare, în comparaţie cu alte metode de training (didactic de exemplu) pentru echipe interprofesionale/interdisciplinare, a fost evaluată într-o recenzie sistematică, care a inclus 12 studii. În 10 dintre cele 12 studii, acest tip de training a îmbunătăţit semnificativ abilităţile nontehnice comparativ cu sesiunile didactice care au analizat cazuri [25].

Posibilitatea de a învăţa şi exersa într-un mediu nepunitiv şi lipsit de riscuri pentru pacient reprezintă un avantaj major al trainingului bazat pe simulare (TBS) [26,27].

TBS este foarte util pentru situaţiile cu frecvenţă de apariţie redusă, dar cu risc crescut pentru pacient, reprezentând posibile ameninţări la adresa siguranţei pacientului [28]. În astfel de situaţii, în care expunerea la cazuri reale este redusă, profesioniştii riscă să piardă sau să nu dobândească nicio- 
dată abilităţile necesare unei intervenţii corespuzătoare $[29,30]$. TBS le oferă acestora şansa de a-şi dezvolta abilităţile şi de a se antrena, pentru a putea face faţă situaţiei când devine necesar.

TBS se desfăşoară în mod obişnuit în centre de simulare, departe de pacienţii reali. Această abordare prezintă avantaje şi dezavantaje. Printre dezavantaje se numără imposibilitatea recreării în centrul de simulare a unor condiţii, frecvent întâlnite în urgenţă, precum zgomotul ambiental, evenimentele distractive, întreruperile repetate, numărul mare al pacienţilor, interacţiunile multiple cu personalul din alte specialităţi. Un alt dezvantaj îl constituie posibila diferenţă între echipamentele utilizate la locul de muncă şi cele din centrul de simulare.

Mai mult, este posibil ca participanţii să fie nevoiţi sa îşi asume alt rol decât cel cu care sunt obişnuiţi la locul de muncă sau accesul la centrul de simulare poate fi limitat din diverse motive (activităţi desfăşurate concomitent, constrângeri legate de timp şi costuri) [31].

Pentru a depăşi parte dintre aceste inconveniente şi pentru că învăţarea este în conexiune strânsă cu contextul experienţei, pasul următor este mutarea simulărilor la locul de muncă [32]. Trainingul bazat pe simulare in situ este ,un training de echipă, desfăşurat în mediul real în care se acordă îngrijiri pacienţilor, utilizând echipamentul şi resursele unităţii în care se desfăşoară simularea şi care implică membri reali ai echipei medicale“ [33].

Un mare avantaj al simulării in situ (SIS) îl constituie posibilitatea identificării erorilor latente din sistem, a celor legate de echipamente, de administrarea medicaţiei, de proceduri şi infrastructură. $\mathrm{O}$ dată identificate, ele trebuie comunicate factorilor de decizie şi celor care lucrează în mediul respectiv, permiţând astfel iniţierea unor de modificări în sistem, cu scopul eliminării erorilor latente înainte ca acestea să producă evenimente adverse [33,34]. Acest lucru nu este posibil dacă simulările au loc în centrul de simulare. De asemenea, SIS permite testarea infrastructurii sistemului [35].

Din păcate, simularea in situ nu este lipsită complet de dezavantaje. În timpul simulărilor, este posibilă interferenţă cu acordarea asistenţei medicale pacienţilor reali, putând fi necesară întreruperea simulării, urmată de eşec în atingerea obiectivelor stabilite. De asemenea, postsimulare trebuie acordată o atenţie sporită participanţilor care au avut performanţe slabe şi s-au întors la locul de muncă, activitatea lor putând fi influenţată negativ [31]. Indiferent de tipul de TBS, simularea trebuie să fie urmată de debriefing, observaţiile participanţilor putând fi benefice pentru îmbunătăţirea siguranţei pacientului. Debriefingul are rolul de a facilita reflexia, reţinerea şi reamintirea $[31,36]$. Este important ca acesta să se desfăşoare sub forma unei discuții colegiale, fără critică destructivă, încurajând schimbul de idei, descărcarea emoţiilor, feedback şi analiză. Când condiţiile tehnice permit, poate fi utilă folosirea înregistrărilor simulărilor pentru a compara informaţii şi a iniţia discuţii.

Utilitatea trainingului CRM combinând sesiunea didactică cu sesiune de simulări, în ameliorarea abilităţilor nontehnice şi a performanţei clinice a echipelor medicale interprofesionale de urgenţă, în condiţii de simulare, a fost testată şi dovedită şi în studiul realizat în 2016 în Unitatea de Primiri Urgenţe din cadrul Spitalului Clinic Judeţean de Urgenţă Târgu Mureş şi în centrul de simulare afiliat acestuia. Acest studiu a combinat simulările in situ, utilizate în scopul evaluării abilităţilor nontehnice individuale şi a performanţei echipei, cu un training de o zi, care a constat într-o prezentare despre erorile medicale şi principiile CRM, urmat de o sesiune de simulări. Pentru sesiunea de simulări din centrul de simulare, au fost folosite manechine de fidelitate înaltă şi echipamentul medical din camera de reanimare a centrului de simulare. $\mathrm{Cu}$ ajutorul unui sistem de transmisie video în timp real cu rezoluţie înaltă, simulările au putut fi urmărite în direct de cei care nu erau direct implicaţi în scenariu, permiţând astfel expunerea tuturor participanţilor la sesiune, la toate scenariile şi efectuarea debriefingului colectiv. Pentru simulările în situ, a fost folosit un manechin de fidelitate înaltă şi echipamentul din camera de reanimare a Unităţii de Primiri Urgenţe. Aceste simulări au fost înregistrare cu o cameră video mobilă, permiţând astfel evaluarea ulterioară.

Impactul acestui training de o zi a fost semnificativ în ceea ce priveşte abilităţile nontehnice ale tuturor participanţilor, indiferent de experienţa lor în serviciul de urgenţă. Performanţa echipei a fost, de asemenea, îmbunătăţită şi, empiric, ar putea avea un impact pozitiv asupra siguranţei şi evoluţiei pacienţilor reali $[37,38]$.

În plus, dacă erorile medicale sunt adesea datorate erorilor umane, putem presupune că o intervenţie educaţională, cum ar fi trainingul CRM, având ca scop îmbunătăţirea comunicării, dinamicii echipei şi reducerii erorilor, ar duce la o îmbunătăţire indirectă şi cel puțin parţială a satisfacţiei la locul de muncă $[39,40]$.

\section{CONCLUZII}

Medicina modernă se bazează pe tehnologie. Utilitatea sistemelor de telemedicină în ameliora- 
rea asistenţei medicale de urgenţă este incontestabilă şi devine din ce în ce mai mult o parte integrantă esenţială a sistemului sanitar.

Învăţarea bazată pe simulare poate fi modul de a dezvolta cunoştinţele şi atitudinile specialiştilor din domeniul sănătăţii, în acelaşi timp protejând pacienţii de riscuri inutile.

Trainingul CRM, care a combinat sesiunile didactice cu sesiunile de simulări, şi-a dovedit

\section{BIBLIOGRAFIE}

1. Hostiuc F, Buciu A. Intergration of Technology in the Multinational Telemedicine System. În A Multinational Telemedicine Systems for Disaster Response. Opportunities and Challenges. IOS Press 2017;ISBN 978-1-61499-727-6:46-47.

2. Ciottone, Gregory R. Disaster medicine (1st ed.). Philadelphia: Elsevier Mosby 2006;ch.50:322-326

3. Farra S, Miller E, Timm N, Schafer J. Improved Training for Disasters Using 3-D Virtual Reality Simulation. Western Journal of Nursing Research 2012;35(5):655-671.

4. Drury J, Coucking C, Reicher S, Burton A, Schofield D, Hardwick A, Graham D, Langston P. Cooperation versus competition in a mass emergency evacuation: A new laboratory simulation and a new theoretical model. Behavior Research Methods 2009;41(3):957-970.

5. Cone DC, Serra J, Kurland L. Comparison of the SALT and Smart triage systems using a virtual reality simulator with paramedic students. European Journal of Emergency Medicine 2011; 18(6):314-321.

6. Heinrichs W.L, Youngblood P, Harter PM, Dev P. Simulation for team training and assessment: Case studies of online training with virtual worlds. World Journal of Surgery 2008;32(2):161-170.

7. Knight, JF, Carley S, Tregunna B, Smithies R, de Freitas S, Dunwell I, Mackway-Jones K. Serious gaming technology in major incident triage training: A pragmatic controlled trial. Resuscitation 2010; 81:1175.

8. Bandura A. Social Cognitive Theory of Mass Communication. In Bryant J, Oliver MB, editors. Media Effects. 3rd ed. New York: Routledge; 2009:110-40.

9. Leder J, Horlitz T, Puschmann P, Wittstock V, Schütz A. Comparing immersive virtual reality and powerpoint as methods for delivering safety training: Impacts on risk perception, learning, and decision making. Saf Sci. 2019;111:271-86.

10. Mantovani F, Castelnuovo G, Gaggioli A, Riva G. Virtual Reality Training for Health-Care Professionals. Cyber Psychology Behav. 2003;6(4):389-95.

11. Baker GR, Norton PG, Flintoft V et al. The Canadian Adverse Events study: the incidence of adverse events among hospital patients in Canada. Can Med Assoc J. 2004;170:1678-86.

12. Aron $D$, Headrick L. Educating physicians prepared to improve care and safety is no accident: it requires systematic approach. Qual Saf Health Care. 2002;11:168-73.

13. Bond Air Services. Helicopter emergency medical service crew member training course manual: crew resource management. Glouchester. Bond Air Services 2002.

14. Bleetman A, Sanusi S, Dale T, Brace S. Human factors and error prevention in emergency medicine. Emerg Med J. 2012;29:389-93.

15. Flin R, Maran N. Basic concepts for crew resource management and non-technical skills. Best Practice \& Research Clinical Anaesthesiology 2015;29:27-39.

16. Helmreich R, Merrit A, Wilhelm J. The evolution of crew resource management training in commercial aviation. Int $\mathrm{J}$ Aviat Psychol. 1999:9:19-32.

17. Petrosoniak A, Hicks CM. Beyond crisis resource management: new frontiers in human factors training for acute care medicine. Curr Opin Anesthesiol. 2013:26:699-706. eficienţa în ameliorarea abilităţilor nontehnice şi a performanţei clinice a echipelor medicale interprofesionale de urgență.

\section{Mențiune}

Toţi autorii au avut contribuţie egală în realizarea acestui articol.

Conflict of interest: none declared Financial support: none declared

18. Rovamo L, Nurmi E, Mattila MM, Suominen P, Silvennoinen M. Effect of a simulation-based workshop on multidisciplinary teamwork of newborn emergencies: an interventional study. BMC Res Notes. 2015;8:671.

19. Kohn LT, Corrigan JM, Donaldson MS; Committee on Quality of Health Care in America, Institute of Medicine. To err is human: building a safer care system. Washington, DC: National Academy Press, 2000

20. Williamson J, Webb R, Sellen A et al. Human failure: an analysis of 2000 incident reports. Anesth Intensive Care. 1993;21:678-83.

21. Hicks MC, Kiss A, Bandiera WG, Denny JC. Crisis Resources for Emergency Workers (CREW II): results of a pilot study and simulation-based crisis resource management course for emergency medicine residents. CJEM 2012;14(6):354-62.

22. Department of Health. Am organization with memory. London: Stationary Office; 2000.

23. Flin R, O'Conner P, Crichton M. Safety at the sharp end: a guide to non-technical skills. Aldershot: Ashgate; 2008.

24. Brown LL, Overly FL. Simulation-Based Interprofessional Team Training. Clin Pediatr Emerg Med. 2016;17(3):179-84.

25. Fung L, Boet S, Bould MD et al. Impact of crisis resource management simulation-based training for interprofessional and interdisciplinary teams: A systematic review. J Interprof. 2015; 29(5):433-44.

26. Ericsson KA, Charness N. Expert performance: its structure and acquisition. Am Psychol. 1994;49:725-47.

27. Raemer D. Team-oriented medical simulation. In: Dunn W, editor. Simulators in critical care education and beyond. Des Plaines, IL: Society of Critical Care Medicine;2004:42-6.

28. Chiniarra G, Cole G, Brisbin K et al. Simulation in healthcare: a taxonomy and a conceptual framework for instructional design and media selection. Med Teach. 2013;35(8):e1380-95.

29. Mittiga MR, Geis GL, Kerrey BT et al. The spectrum and frequency of critical procedures performed in a pediatric emergency department: implication of provider-level view. Ann Emerg Med. 2013;61:263-70.

30. Overly FL, Sudikoff SN, Shapiro MJ. High-fidelity medical simulation as an assessment tool for pediatric residents'airway management skills. Pediatr Emerg Care. 2007;23:11-5.

31. Petronosiak A, Auerbach $\mathrm{M}$, Wong $\mathrm{AH}$ et al. In situ simulation in emergency medicine: Moving beyond the simulation lab. Emerg Med Austral. 2017;29:83-8.

32. Durning SJ, Artini AR. Situativity theory: a perspective on how participants and the environment can interact: AMEE guide no. 52 . Med Teach. 2011;33:188-99.

33. Patterson MD, Geis GL, Falcone RA et al. In situ simulation: detection of safety threats and teamwork training in the high risk emergency department. BMJ Qual Saf. 2013;22:468-77.

34. Auerbach M, Kessler DO, Patterson M. The use of in situ simulation to detect latent safety threats in paediatrics: a cross-sectional survey. BMJ Simulation and Technology Enhanced Learning 2015;1:77-82.

35. Cheng A, Grant V, Auerbach M. Using simulation to improve patient safety: dawn of the new era. JAMA Pediatr. 2015;169:419-20. 
36. Issenberg S, McGaghie W, Petrusa A et al. Feature and uses of high-fidelity medical simulations that lead to effective learning: a BEME systematic review. Med Teach. 2005;27:10-28.

37. Truta TS, Boeriu CM, Copotoiu SM et al. Improving nontechnical skills of an interprofessional emergency medical team through a one day crisis resource management. Medicine 2018;32:(e11828).

38. Truta TS, Boeriu CM, Lazarovici M et al. Improving Clinical Performance of an Interprofessional Emergency Team through a One-day Crisis Resource Management Training. JCCM 2018.
39. Carne B, Kennedy M, Gray T. Crisis resource management in emergency medicine. Emerg Med Austral. 2012;24:7-13.

40. Truta TS, Ban I, BoeriuC et al. Impact of a One Day Crisis Resource Management Training on the Work Satisfaction among Emergency Department Healthcare Staff. Acta Med Marisiensis. 2018; 64(3):95-102. 